\title{
HER2-positive gastric cancer identified by serum HER2: A case report
}

\author{
MAYUKO SAITO, YUJIRO KAWAKAMI, KENTARO YAMASHITA, HIROSHI NASUNO, YU ISHIMINE, \\ KOICHIRO FUKUDA, HIROYUKI ISSHIKI, RYO SUZUKI, YOSHIAKI ARIMURA and YASUHISA SHINOMURA
}

Department of Gastroenterology, Rheumatology and Clinical Immunology,

Sapporo Medical University, Sapporo, Hokkaido 060-8543, Japan

Received January 5, 2015; Accepted February 5, 2016

DOI: $10.3892 / 01.2016 .4470$

\begin{abstract}
Immunohistochemistry (IHC) and fluorescence in situ hybridization (FISH) are the current standards methods for the determination of tissue human epidermal growth factor receptor 2 (HER2) status in gastric cancer, as for breast cancer. However, HER2-positive gastric cancer occasionally exhibits heterogeneous tissue HER2 overexpression, raising concern regarding false-negative results in unresectable cases diagnosed by biopsy samples. Serum HER2, the concentration of the extracellular domain of HER2 protein shed into the bloodstream, has the potential to supplement the use of IHC or FISH to determine HER2 status. However, the clinical significance of serum HER2 has not been well studied in gastric cancer. The present study describes an illustrative case of metastatic gastric cancer initially diagnosed as HER2-negative (IHC score 1+). The patient exhibited an elevated serum HER2 level, which prompted a reevaluation of the tissue by IHC, using an alternative antibody, and FISH; re-biopsy analyses confirmed the case as HER2-positive, and trastuzumab was subsequently added to the combination chemotherapy with capecitabine and cisplatin. Serum HER 2 may aid in avoiding false-negative diagnoses of HER2 gastric cancer.
\end{abstract}

\section{Introduction}

Since the international phase III trial demonstrating the survival benefit of trastuzumab for patients with human epidermal growth factor receptor 2 (HER2)-positive gastric cancer (1), tissue HER2 assessment has become a routine practice in patients with advanced gastric cancer. In contrast to

Correspondence to: Dr Mayuko Saito, Department of Gastroenterology, Rheumatology and Clinical Immunology, Sapporo Medical University, S1, W16 Chuo-ku, Sapporo, Hokkaido 060-8543, Japan

E-mail:mayu.921@apost.plala.or.jp; m.saitou@sapmed.ac.jp

Key words: serum HER2, gastric cancer, intratumoral heterogeneity, HER2 overexpression, sampling error, false-negative
HER2-positive breast cancer, which generally exhibits homogenous HER2 overexpression, gastric cancer frequently exhibits intratumoral heterogeneity of HER2 overexpression (2-5). In addition, recent studies have demonstrated substantial inter-laboratory, as well as inter-observer discordance in tissue HER 2 assessments (6,7). This may be responsible for generating HER2 false-negative results, depriving the patient of the opportunity for anti-HER 2 treatment.

Serum HER2 is the HER2 extracellular domain that sheds from the surface of cancer cells into the circulation, and may be quantified by chemiluminescence immunoassay (CLIA). The clinical significance of serum HER2 has been reported in breast cancer (8-13); however, few studies have investigated this in gastric cancer. The current report presents our experience with an illustrative case of HER2-positive metastatic gastric cancer that was initially diagnosed as HER2-negative and salvaged by serum HER2.

\section{Case report}

In October 2012, a 56-year-old male presented to Sapporo Medical University Hospital (Sapporo, Japan) with dysphagia and weight loss. The patient's past history was unremarkable, and physical examination revealed mild epigastric tenderness and a palpable liver. The baseline laboratory tests demonstrated elevated liver enzymes (aspartate transaminase, $148 \mathrm{IU} / 1$, normal range, 11-39 IU/1; alanine transaminase, $89 \mathrm{IU} / 1$, normal range, 5-40 IU/l; alkaline phosphatase, 1,292 IU/1, normal range, 110-370 IU/1; and lactate dehydrogenase, 2,976 IU/1, normal range, 119-229 IU/1) and elevated carbohydrate antigen 19-9 (131.9 U/ml; normal range, 0.0-37.0 U/ml). Upper gastrointestinal endoscopy revealed a Borrmann type III cancer (14) from the cardia to the lower esophagus (Fig. 1A), and computed tomography (CT) imaging revealed multiple liver and nodal metastases (Fig. 1B). The pathological diagnosis of three biopsy specimens was moderately to poorly differentiated tubular adenocarcinoma. Immunohistochemistry (IHC) for HER2 was performed on formalin-fixed, 4- $\mu \mathrm{m}$ thick, paraffin-embedded tissue sections (SurgiPath Paraplast; Leica Biosystems, Wetzlar, Germany) using a monoclonal rabbit PATHWAY anti-HER2 antibody (4B5; Bench Mark GX; Roche Diagnostics K.K., Tokyo, Japan). The tissue yielded a score of $1+$ according to a scoring 
A

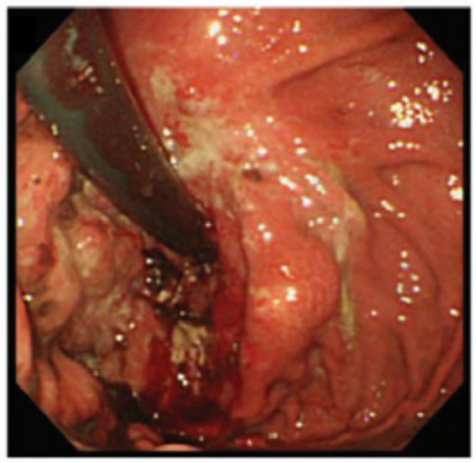

B

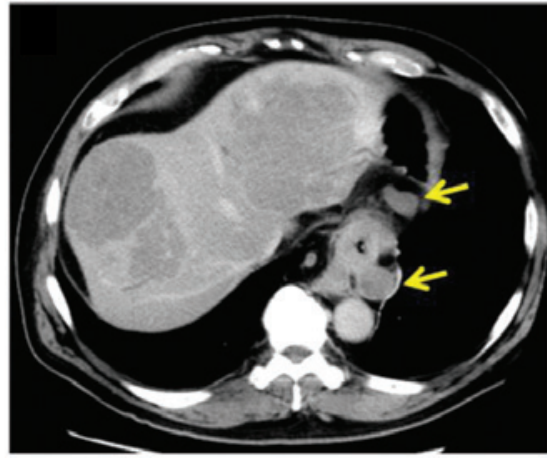

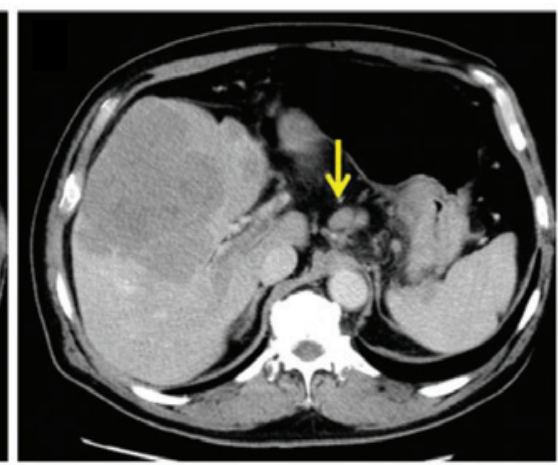

Figure 1. Imaging examinations. (A) Gastrointestinal endoscopy revealed a type 3 lesion in the cardia region. (B) Computed tomography imaging prior to chemotherapy revealed multiple liver and nodal metastases (arrows).

A

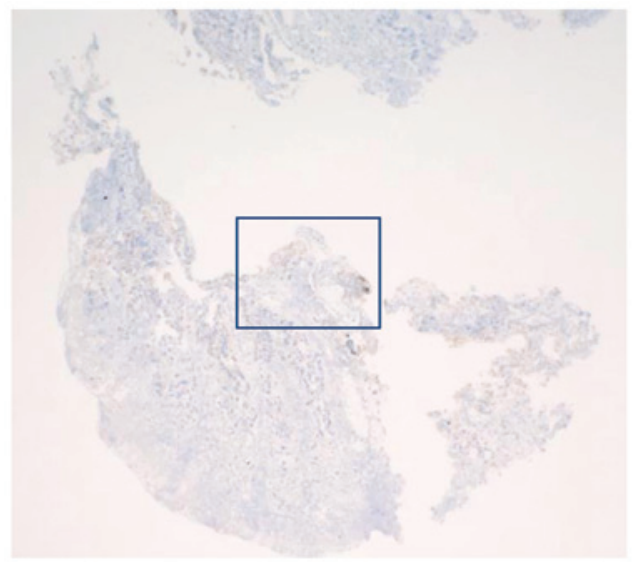

B

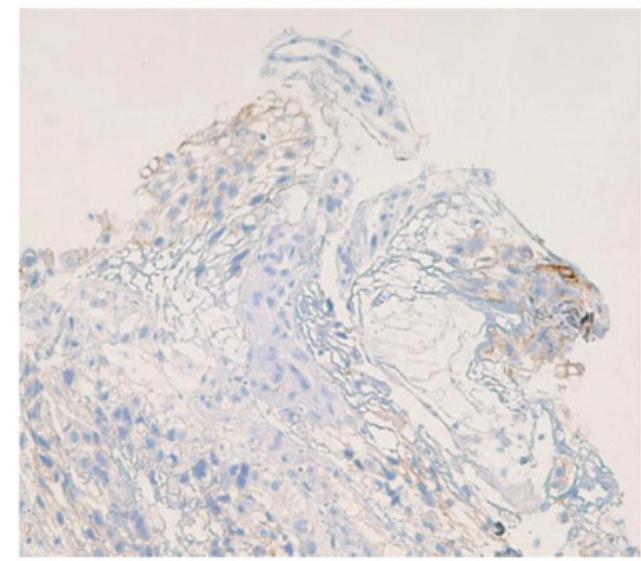

Figure 2. Initial human epidermal growth factor receptor 2 immunohistochemistry. Barely perceptible membrane staining (score $1+$ ) was observed. (A) $\mathrm{x} 40$ and (B) x200 magnification.
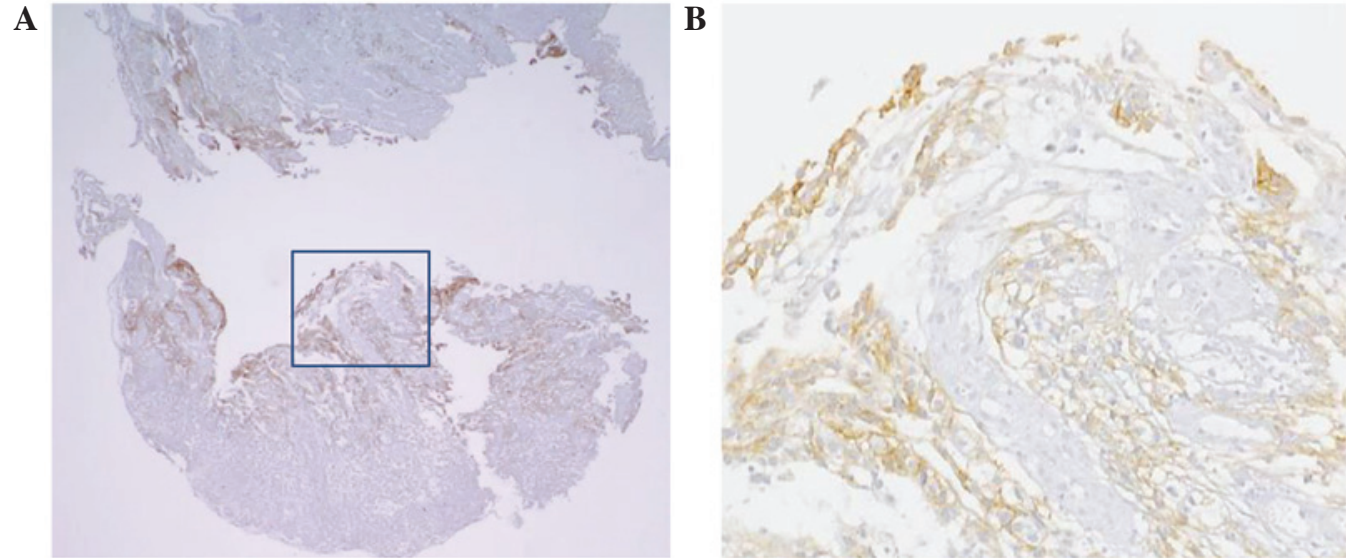

Figure 3. Second human epidermal growth factor receptor 2 immunohistochemistry. An alternative monoclonal antibody (HercepTest ${ }^{\mathrm{TM}}$ ) revealed numerous tumor cell clusters with strong complete membrane staining (scored as 3+). (A) x40 and (B) x200 magnification.

criteria specifically developed for gastric cancer (2). Staining was scored as follows: 0 , no reactivity or no membrane staining; +1 , tumor cell cluster with a faint/barely perceptible membranous reactivity; +2 , tumor cell cluster with a weak to moderate complete, basolateral, or lateral membranous reactivity; +3 , tumor cell cluster with a strong complete, basolateral, or lateral membranous reactivity. Tissues with a score of +3 or +2 in addition to fluorescence in situ hybridization
(FISH) positivity were considered as HER 2 positive. Thus, the patient was diagnosed as HER2-negative (Fig. 2). Based on this diagnosis, $\mathrm{S}-1$ plus cisplatin combination chemotherapy (S-1, $40 \mathrm{mg} / \mathrm{m}^{2}$, twice daily, days 1-21; cisplatin, $60 \mathrm{mg} / \mathrm{m}^{2}$, day 8 , every 5 weeks) was commenced.

The patient was enrolled onto our clinical trial investigating the association between serum HER 2 and tissue HER2 status in gastric cancer (15). The serum HER2 level of this patient 


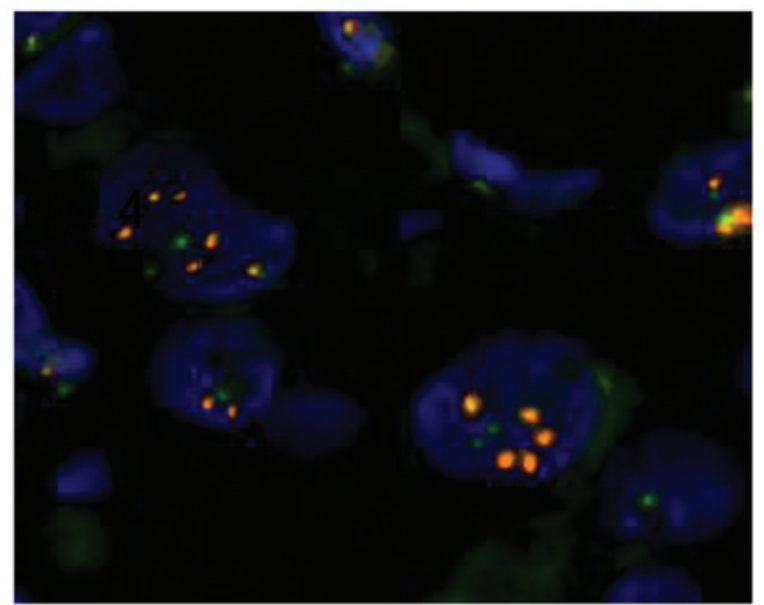

Figure 4. Fluorescence in situ hybridization analysis revealed a high level HER2 amplification. The ratio of HER-2/neu signal (orange) to centromere 17 signal (green) was 2:48.

measured by CLIA (ADVIA Chemilumi-Centaur-HER2/neu assay $^{\mathrm{TM}}$; Siemens Healthcare Diagnostics, Tokyo, Japan) was $53.3 \mathrm{ng} / \mathrm{ml}$, which was higher than the upper limit of normal for breast cancer $(15.2 \mathrm{ng} / \mathrm{ml})$. In addition to the clinical features consistent with HER2-positive gastric cancer, such as the junctional location, differentiated histology and liver metastasis, the elevated serum HER2 level prompted the reevaluation of the tissue HER2 status.

The second IHC analysis, performed on formalin-fixed, 4- $\mu \mathrm{m}$ thick, paraffin-embedded tissue sections using an alternative polyclonal rabbit antibody from the HercepTest ${ }^{\mathrm{TM}}$ kit (Dako A/S, Glostrup, Denmark), demonstrated intensive membranous staining, judged to be HER2 score 3+ (Fig. 3). In addition, the HER2/chromosome 17 centromere ratio assessed by FISH was 2.48, also interpreted as HER2-positive (Fig. 4). Four biopsy samples were additionally taken at a follow-up endoscopy, and IHC for these re-biopsy specimens also confirmed a HER2 score of 3+ (Fig. 5). Based on the final diagnosis, the treatment protocol was changed from S-1 plus cisplatin to capecitabine, cisplatin and trastuzumab combination chemotherapy $(\mathrm{XP}+\mathrm{H}$; capecitabine, 2,000 mg/m², twice daily, days 1-14; cisplatin, $80 \mathrm{mg} / \mathrm{m}^{2}$, day 1 , every 3 weeks; trastuzumab, $8 \mathrm{mg} / \mathrm{kg}$ in the first cycle followed by $6 \mathrm{mg} / \mathrm{kg}$, day 1) from the third course of chemotherapy. This regimen was well-tolerated, with grade 1 fatigue and grade 1 anorexia observed (16). The patient's symptoms were greatly relieved by the treatment, and $\mathrm{CT}$ imaging demonstrated regression of liver as well as nodal metastases. A partial response was maintained for four months; however, the disease progressed following 5 cycles of $\mathrm{XP}+\mathrm{H}$. Despite second and third-line treatment [paclitaxel $\left(80 \mathrm{mg} / \mathrm{m}^{2}\right.$ on days 1,8 and 15 , every 4 weeks) and nab-paclitaxel $\left(260 \mathrm{mg} / \mathrm{m}^{2}\right.$, every 3 weeks) respectively], the patient succumbed to the disease 10 months after the initial presentation.

\section{Discussion}

Past studies have demonstrated that $7-34 \%$ of gastric cancer cases overexpress HER2 (17-19), and the rate was reported to be $22 \%$ in a recent large-scale international prospective
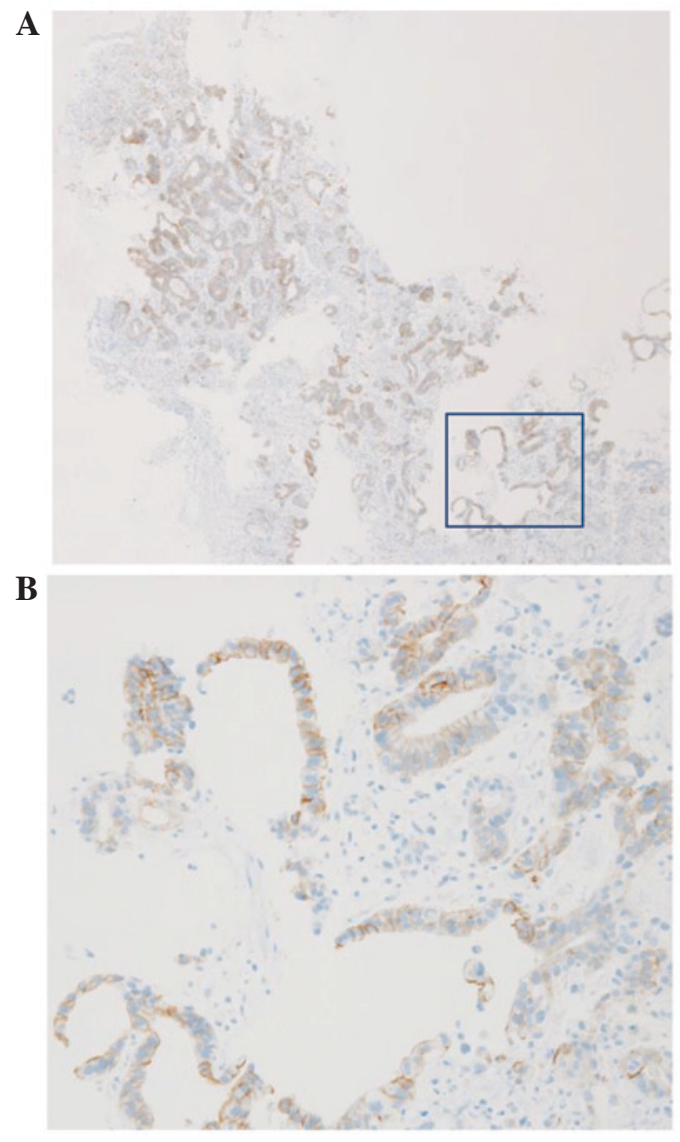

Figure 5. Immunohistochemical analysis of human epidermal growth factor receptor 2 in the re-biopsy specimens revealed strong complete membrane staining (scored as 3+). (A) x40 and (B) x200 magnification.

trial (1). Since the introduction of trastuzumab, standardization and optimization of HER2 testing has been highlighted in the management of advanced gastric cancer. However, HER 2 assessment by IHC and FISH present a substantial risk of false-negative results for gastric cancer, particularly when biopsy samples were used for the diagnosis (i.e. unresectable cases) (2-7). Serum HER2, a simple and less invasive method, assesses a different aspect of HER2 status from IHC and FISH. Although the clinical utility of serum HER2 in gastric cancer remains uncertain, a number of investigators have reported that serum HER2 level correlates with tissue HER2 status in gastric cancer (15,20-22). In the present case, the high serum HER2 level was the primary reason for the IHC reevaluation, and tissue HER 2 positivity was eventually proven. Discrepancy of the IHC results may be due to use of a different primary antibody, as the same biopsy samples were used for the initial and second IHC.

There are numerous risk factors for diagnostic error of HER2 status in gastric cancer, including insufficient number of biopsy specimens, inadequate formalin fixation protocol, inexperienced laboratory staff and intratumoral HER2 heterogeneity (2-7). As trastuzumab has demonstrated a significant positive effect on treatment for unresectable HER2-positive gastric cancer, efforts must be made to minimize HER2 false-negative cases. Recent reviews concluded that serum HER2 is not useful for breast cancer management $(11,23)$. However, serum HER2 may be useful to identify HER2 
false-negative gastric cancer as HER2 overexpression in gastric cancer is frequently heterogeneous.

In conclusion, in the present case, serum HER2 was useful to identify a HER2-positive gastric cancer that was initially diagnosed as HER2-negative by IHC. This case suggests that serum HER2 may be useful to salvage tissue HER2 false-negative patients who are able to benefit from anti-HER2 treatment. Serum HER2 is expected to compensate for the aforementioned drawbacks of IHC in gastric cancer management. Large scale prospective studies are required.

\section{References}

1. Bang YJ, Van Cutsem E, Feyereislova A, Chung HC, Shen L, Sawaki A, Lordick F, Ohtsu A, Omuro Y, Satoh T, et al: Trastuzumab in combination with chemotherapy versus chemotherapy alone for treatment of HER2-positive advanced gastric or gastro-oesophageal junction cancer (ToGA): A phase 3, open-label, randomised controlled trial. Lancet 376: 687-697, 2010

2. Hofmann M, Stoss O, Shi D, Büttner R, van de Vijver M, Kim W, Ochiai A, Rüschoff J and Henkel T: Assessment of a HER2 scoring system for gastric cancer: Results from a validation study. Histopathology 52: 797-805, 2008.

3. Yang J, Luo H, Li Y, Li J, Cai Z, Su X, Dai D, Du W, Chen T and Chen M: Intratumoral heterogeneity determines discordant results of diagnostic tests for human epidermal growth factor receptor (HER) 2 in gastric cancer specimens. Cell Biochem Biophys 62: 221-228, 2012.

4. Lee HE, Park KU, Yoo SB, Nam SK, Park do J, Kim HH and Lee HS: Clinical significance of intratumoral HER2 heterogeneity in gastric cancer. Eur J Cancer 49: 1448-1457, 2013

5. Rüschoff J, Hanna W, Bilous M, Hofmann M, Osamura RY, Penault-Llorca F, van de Vijver M and Viale G: HER2 testing in gastric cancer: A practical approach. Mod Pathol 25: 637-650, 2012

6. Huang D, Lu N, Fan Q, Sheng W, Bu H, Jin X, Li G, Liu Y, Li X, Sun W, et al: HER2 status in gastric and gastroesophageal junction cancer assessed by local and central laboratories: Chinese results of the HER-EAGLE study. PLoS One 8: e80290, 2013.

7. Kushima R, Kuwata T, Yao T, Kuriki H, Hashizume K, Masuda S, Tsuda $\mathrm{H}$ and Ochiai A: Interpretation of HER2 tests in gastric cancer: Confirmation of interobserver differences and validation of a QA/QC educational program. Virchows Arch 464: 539-545, 2014

8. Carney WP, Neumann R, Lipton A, Leitzel K, Ali S and Price CP: Monitoring the circulating levels of the HER2/neu oncoprotein in breast cancer. Clin Breast Cancer 5: 105-116, 2004.

9. Fornier MN, Seidman AD, Schwartz MK, Ghani F, Thiel R, Norton L and Hudis C: Serum HER2 extracellular domain in metastatic breast cancer patients treated with weekly trastuzumab and paclitaxel: Association with HER2 status by immunohistochemistry and fluorescence in situ hybridization and with response rate. Ann Oncol 16: 234-239, 2005.
10. Finn RS, Gagnon R, Di Leo A, Press MF, Arbushites M and Koehler M: Prognostic and predictive value of HER2 extracellular domain in metastatic breast cancer treated with lapatinib and paclitaxel in a randomized phase III study. J Clin Oncol 27: 5552-5558, 2009.

11. Lennon S, Barton C, Banken L, Gianni L, Marty M, Baselga J and Leyland-Jones B: Utility of serum HER2 extracellular domain assessment in clinical decision making: Pooled analysis of four trials of trastuzumab in metastatic breast cancer. J Clin Oncol 27: 1685-1693, 2009.

12. Leary AF, Hanna WM, van de Vijver MJ, Penault-Llorca F, Rüschoff J, Osamura RY, Bilous M and Dowsett M: Value and limitations of measuring HER-2 extracellular domain in the serum of breast cancer patients. J Clin Oncol 27: 1694-1705, 2009.

13. Kontani K, Kuroda N, Hashimoto S, Murazawa C, Norimura S, Tanaka H, Ohtani M, Fujiwara-Honjo N, Kushida Y, Date M, et al: Clinical usefulness of human epidermal growth factor receptor-2 extracellular domain as a biomarker for monitoring cancer status and predicting the therapeutic efficacy in breast cancer. Cancer Biol Ther 14: 20-28, 2013.

14. Borrmann R: Geschwülste des Magens und Duodenums, Makroskopische Formen. Henke u. Lubarsch. Handbuch d. sp. Path. usw., 1/IV: 864-871, 1926.

15. Saito M, Yamashita K, Arimura Y, Kaneto H, Okuda H, Nojima M, Hagiwara T, Suzuki K, Adachi T, Goto A, et al: Serum HER2 as an adjunct to assess HER2 status for advanced gastric cancer: A prospective multicenter trial (SHERLOCK). Acta Oncol 55: 309-17, 2016.

16. National Cancer Institute: Common Terminology Criteria for Adverse Events (CTCAE). Version 4.0. http://evs.nci.nih.gov/ ftp1/CTCAE/CTCAE_4.03_2010-06-14_QuickReference_5x7. pdf. Accessed, 5th January 2014.

17. Gravalos $C$ and Jimeno A: HER2 in gastric cancer: A new prognostic factor and a novel therapeutic target. Ann Oncol 19: 1523-1529, 2008.

18. Hofmann M, Stoss O, Shi D, Büttner R, van de Vijver M, Kim W, Ochiai A, Rüschoff J and Henkel T: Assessment of a HER2 scoring system for gastric cancer: Results from a validation study. Histopathology 52: 797-805, 2008.

19. Tanner M, Hollmén M, Junttila TT, Kapanen AI, Tommola S, Soini Y, Helin H, Salo J, Joensuu H, Sihvo E, et al: Amplification of HER-2 in gastric carcinoma: Association with Topoisomerase IIalpha gene amplification, intestinal type, poor prognosis and sensitivity to trastuzumab. Ann Oncol 16: 273-278, 2005.

20. Dai SQ, An X, Wang F, Shao Q, Chen YC, Kong YN, Chen C, Li C, Luo HY, Liang Y, et al: Serum HER 2 extracellular domain level is correlated with tissue HER 2 status in metastatic gastric or gastro-oesophageal junction adenocarcinoma. PloS One 8: e63458, 2013

21. Narita T, Seshimo A, Suzuki M, Murata J and Kameoka S: Status of tissue expression and serum levels of HER2 in gastric cancer patients in japan. Hepatogastroenterology 60: 1083-1088, 2013.

22. Oyama K, Fushida S, Tsukada T, Kinoshita J, Watanabe T, Shoji M, Nakanuma S, Okamoto K, Sakai S, Makino I, et al: Evaluation of serum HER2-ECD levels in patients with gastric cancer. J Gastroenterol 50: 41-45, 2015.

23. Leyland-Jones B and Smith BR: Serum HER2 testing in patients with HER 2-positive breast cancer: The death knell tolls. Lancet Oncol 12: 286-295, 2011. 